\title{
ELIMINAÇÃO DE COMPOSTOS ORGÂNICOS VOLÁTEIS POR MEIO DE ABSORÇÃO EM ÓLEO EM COLUNAS DE ENCHIMENTO
}

\author{
L. G. RIBEIRO ${ }^{1, *}$, H. S. MONTEIRO ${ }^{1}$, N. S. DENARDI ${ }^{1}$, W. HUNG-HSU ${ }^{1}$ e \\ Y. C. ROCHA ${ }^{1}$ \\ ${ }^{1}$ Centro Universitário FEI, Departamento de Engenharia Química \\ *E-mail: luciano.ribeiro0312@gmail.com
}

\begin{abstract}
RESUMO: Este trabalho propôs o estudo do desempenho de colunas de enchimento a fim de se reduzir a emissão de VOC presentes em correntes gasosas industriais por meio de absorção em solvente adequado. Devido a esses compostos serem hidrofóbicos, os solventes foram selecionados por serem semelhantes aos VOC quanto à polaridade e foram: óleo de soja, de reuso, de silicone e de rícino. A metodologia consistiu em ensaios em uma coluna de absorção de escala laboratorial, mantendo-se os mesmos parâmetros operacionais entre cada experimento. Utilizando-se esses parâmetros e características físicas dos equipamentos laboratoriais, os resultados experimentais foram confrontados com os obtidos pelas simulações no Aspen Plus para a possibilidade de aplicação em processo real. Através do desempenho de absorção e critérios ambientais e econômicos, o óleo de reuso apresentou melhor potencial para esse fim por se tratar de um resíduo químico que pode ser utilizado para amenizar o problema ambiental em questão.
\end{abstract}

PALAVRAS-CHAVE: Compostos orgânicos voláteis (VOC); Tolueno; Absorção; Óleo; Coluna de enchimento.

\section{INTRODUÇÃO}

Os compostos orgânicos voláteis, conhecidos como VOC (volatile organic compounds) são assim denominados por apresentarem baixo ponto de ebulição e alta toxicidade para o meio ambiente. Tais substâncias não podem ser reutilizadas em processos, necessitando descarte apropriado e que acabam comumente vendidas e posteriormente usadas como combustível.

A emissão de compostos orgânicos voláteis por indústrias químicas vem crescendo à medida que a demanda por produtos que os liberam aumenta, causando problemas de poluição nas áreas próximas a essas empresas e afetando não só o meio ambiente, mas também as condições de trabalho dos funcionários. Os VOC são desprendidos como subprodutos de reações principalmente nas indústrias de materiais poliméricos, refinarias e indústrias produtoras de tintas e vernizes (OU, 2015). 
A liberação de VOC deve ser controlada e monitorada pelos órgãos competentes em cada país. No Brasil, esse monitoramento é feito pela Companhia de Tecnologia e Saneamento Ambiental (CETESB) que visa garantir níveis mínimos possíveis de emissão devido as suas toxicidades (SÃO PAULO, 1976).

A qualidade da emissão atmosférica de correntes gasosas dentro dos padrões legais pode ser garantida por um processo chamado RTO (regenerative thermal oxidizer - oxidador térmico regenerativo). Entretanto, por se tratar de um processo de combustão, apresenta significante risco de incêndio e explosão para a indústria, apesar do calor gerado na combustão ser reaproveitado no processo. Devido a esse risco, uma outra alternativa para o tratamento de correntes contaminadas é através de absorção por solventes apropriados, uma vez que reduz a taxa de liberação de VOC para o meio ambiente com um menor custo de operação, além da possibilidade de posterior recuperação dos solventes (DARRACQ, 2010).

Por essas razões e pelo impacto ambiental causado pela emissão de VOC, o projeto fundamentou-se no estudo sobre colunas de absorção gasosa e na determinação do solvente mais apropriado para a absorção em sistemas industriais reais através de dados experimentais obtidos em escala de bancada e resultados de simulações computacionais.

\section{MATERIAIS E MÉTODOS}

\subsection{Materiais}

Substâncias: Devido ao fato de VOC apresentarem caráter hidrofóbico, água ou mistura aquosa não podem ser analisados como possibilidade de solvente. Portanto, para o início do projeto, os seguintes solventes foram selecionados considerando suas características também hidrofóbicas e, consequentemente, absorvedoras: óleo de soja (comestível), óleo de reuso (automotivo usado), óleo de silicone (polidimetilsiloxano) e óleo de rícino (mamona).

Além disso, outros critérios para essa decisão foram suas disponibilidades e seus valores comerciais menores que o óleo de silicone, o qual foi citado por trabalhos como de DUMONT et al. (2011).

Dentre as substâncias que compõem os VOC, tolueno foi adotado como molécula representativa, pois considerando a possibilidade de uma comparação prática laboratorial com real, pode ser adquirido com maior facilidade, além de também ter sido utilizado nos estudos de Dumont et al. (2011) e Vuong et al. (2009).

Vidrarias e equipamentos: $O$ fluxograma de processo esquematizado na Figura 1 apresenta a montagem da prática laboratorial desenvolvida para a aquisição das amostras para análise de dados práticos.

A partir do esquema representado pela Figura 1, a vidraria foi selecionada para a montagem do processo conforme disponibilidade no almoxarifado do Centro de Laboratórios Químicos da FEI, não havendo cálculos prévios a respeito das dimensões dos equipamentos, uma vez que os resultados experimentais haveriam de ser comparados com os resultados do mesmo processo gerado no simulador nas mesmas condições laboratoriais. Adiante, o Quadro 1 apresenta e detalha as respectivas identificações numéricas de cada material 
utilizado.

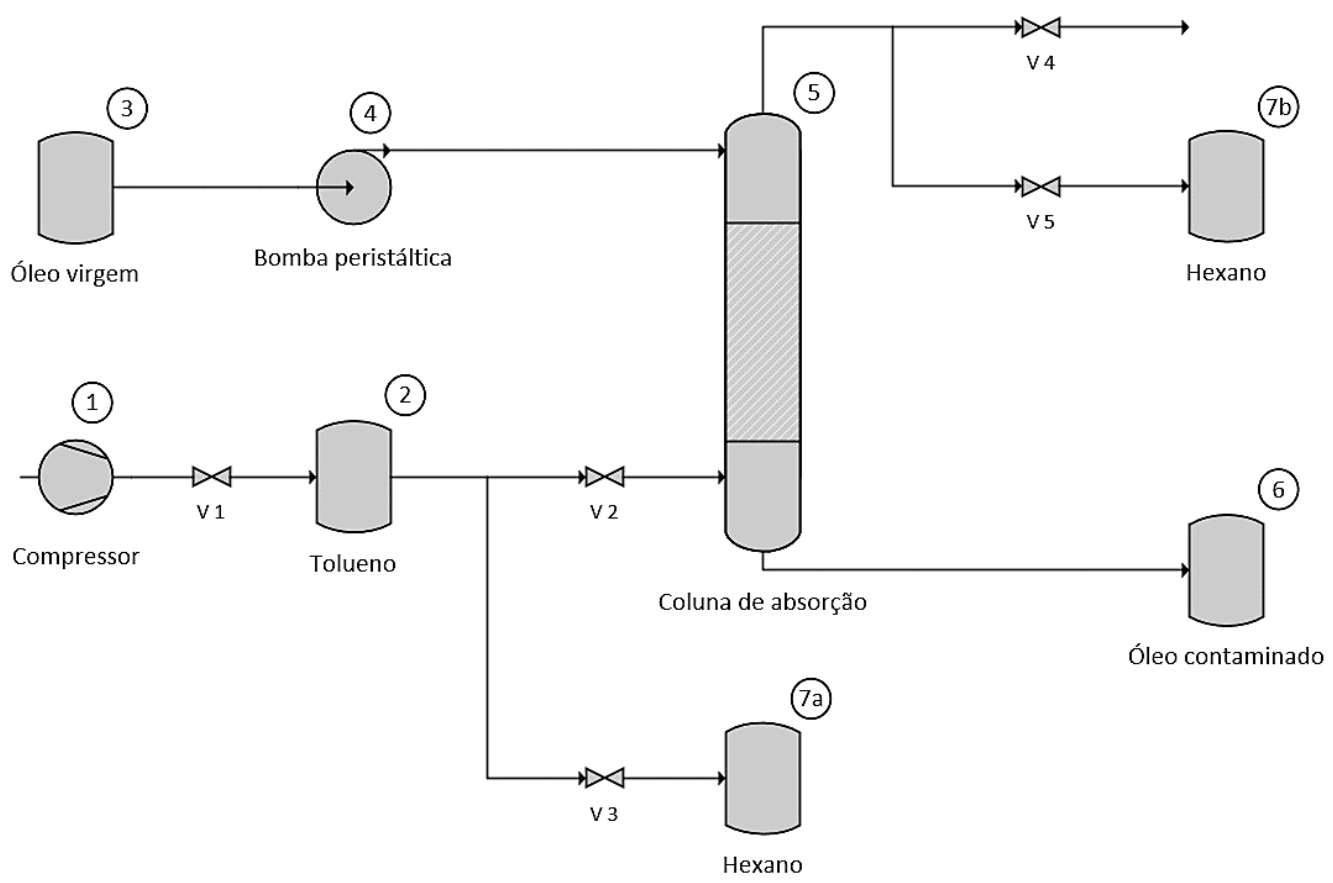

Figura 1 - Fluxograma da unidade laboratorial para dados experimentais.

Quadro 1 - Detalhes das vidrarias e equipamentos da prática laboratorial.

\begin{tabular}{|c|c|c|}
\hline Equipamento & Descrição & Função \\
\hline 1 & Compressor de ar & Criar corrente gasosa de ar atmosférico. \\
\hline 2 & $\begin{array}{l}\text { Frasco lavador contendo } \\
\text { tolueno }\end{array}$ & Saturar a corrente gasosa com tolueno. \\
\hline 3 & $\begin{array}{l}\text { Erlenmeyer contendo óleo } \\
\text { virgem }\end{array}$ & $\begin{array}{l}\text { Dispor de óleo novo a ser utilizado para absorção de } \\
\text { tolueno. }\end{array}$ \\
\hline 4 & Bomba peristáltica & Bombear óleo virgem para a coluna de absorção. \\
\hline 5 & $\begin{array}{l}\text { Coluna de absorção de } \\
\text { Hempel contendo anéis de } \\
\text { Rasching }\end{array}$ & $\begin{array}{l}\text { Permitir contato entre fases para absorção do } \\
\text { contaminante. }\end{array}$ \\
\hline 6 & $\begin{array}{l}\text { Balão de fundo redondo } \\
\text { para óleo contaminado }\end{array}$ & $\begin{array}{l}\text { Receber óleo que sai da coluna contendo tolueno } \\
\text { absorvido. }\end{array}$ \\
\hline $7 \mathrm{a}$ & $\begin{array}{l}\text { Frasco lavador contendo } \\
\text { hexano }\end{array}$ & Absorver tolueno da corrente gasosa de entrada. \\
\hline $7 \mathrm{~b}$ & $\begin{array}{l}\text { Frasco lavador contendo } \\
\text { hexano }\end{array}$ & $\begin{array}{l}\text { Absorver tolueno remanescente na corrente gasosa } \\
\text { de saída. }\end{array}$ \\
\hline V1 & Válvula agulha 1 & $\begin{array}{l}\text { Controlar e fixar o fluxo da corrente gasosa de } \\
\text { entrada. }\end{array}$ \\
\hline $\mathrm{V} 2$ e V3 & Válvulas 2 e 3 & $\begin{array}{l}\text { Direcionar a corrente gasosa de entrada para a } \\
\text { coluna ou frasco } 7 \mathrm{a} \text {. }\end{array}$ \\
\hline V4 e V5 & Válvulas 4 e 5 & $\begin{array}{l}\text { Direcionar a corrente gasosa de saída para a } \\
\text { atmosfera ou frasco } 7 \mathrm{~b} \text {. }\end{array}$ \\
\hline
\end{tabular}

Com o intuito de aumentar a área de contato entre as fases líquida (solvente óleo) e gasosa (contaminante tolueno), a coluna de absorção de Hempel foi preenchida com anéis de 
vidro de Rasching. As dimensões da coluna de laboratório contendo o enchimento eram de exatos $47 \mathrm{~cm}$ de altura e $20 \mathrm{~mm}$ de diâmetro, sendo os anéis de $10 \mathrm{~mm}$ de diâmetro.

As vidrarias e os equipamentos foram todos interligados por mangueiras de silicone e as explicações do funcionamento do processo prático se encontram no tópico seguinte.

\subsection{Procedimento laboratorial}

O procedimento para a coleta das composições de entrada e saída foram realizados em triplicata para cada óleo utilizado com o intuito de garantir a confiabilidade dos resultados.

Composições de entrada: Os dados experimentais obtidos através do sistema foram basicamente as concentrações de tolueno em hexano de entrada e saída da coluna de absorção para o cálculo das composições do contaminante nas correntes gasosas.

Para a obtenção das composições de entrada, seguindo o conceito do fluxograma da Figura 1, a corrente gasosa gerada pelo compressor de ar (1) foi conduzida ao frasco lavador contendo tolueno (2) para a saturação da corrente de entrada. Nesse momento, a válvula 2 (V2) se encontrava aberta e a válvula 3 (V3) fechada para que essa corrente seguisse apenas para a coluna de Hempel (5).

Considerando-se que, em 5 minutos de funcionamento do compressor, o ar inicial presente nas conexões e no frasco lavador foi totalmente expelido pela corrente contaminada com tolueno, a mesma foi direcionada para o frasco lavador contendo hexano (7a) pelo rápido fechamento da válvula 2 (V2) e rápida abertura da válvula 3 (V3). O hexano tem a função de absorver o tolueno gasoso para que, através de uma alíquota do frasco (7a), fosse determinada a concentração de tolueno em hexano através de análise por cromatografia gasosa (CG).

O tempo que a corrente proveniente do frasco (2) permaneceu no sentido do frasco lavador (7a) foram de exatos 60 segundos para que o volume de $150 \mathrm{~mL}$ de hexano não variasse por consequência do arraste devido à corrente gasosa, mas fosse suficiente para a absorção do contaminante que também não afeta no volume da mistura. Por consequência da duração dessa etapa, adotou-se ainda o conceito de solução diluída para que a concentração fosse dada em miligramas de tolueno por mililitro de hexano ( $\mathrm{mg}$ tol/mL hex).

Assim, conhecendo-se a vazão da corrente gasosa de ar e a concentração de tolueno em hexano durante 1 minuto, a composição molar de entrada na coluna de absorção foi obtida conforme as Equações 1, 2 e 3 para ser aplicada como dados de entrada nas simulações computacionais.

$$
\begin{aligned}
& y_{t o l}=\frac{\dot{n}_{t o l}}{\dot{n}_{t o l}+\dot{n}_{a r}} \\
& \dot{n}_{a r}=\frac{P \dot{V}_{a r}}{R T_{a r}}
\end{aligned}
$$




$$
\dot{n}_{\text {tol }}=\frac{C_{\text {tol } / h e x} V_{\text {hex }}}{t_{\text {tol }} M_{\text {tol }}} 10^{-3}
$$

Onde: $y_{t o l}$ - fração molar de tolueno na corrente gasosa, $\dot{n}_{t o l}$ - vazão molar de tolueno na corrente gasosa $\left[\mathrm{mol} \cdot \mathrm{s}^{-1}\right] ; \dot{n}_{a r}$ - vazão molar de ar na corrente gasosa $\left[\mathrm{mol} \cdot \mathrm{s}^{-1}\right], P$ - pressão atmosférica [atm], $\dot{V}_{a r}$ - vazão média de ar $\left[\mathrm{L} \cdot \mathrm{s}^{-1}\right], R$ - constante universal dos gases perfeitos $\left[0,08206 \mathrm{~atm} \cdot \mathrm{L} \cdot \mathrm{mol}^{-1} \cdot \mathrm{K}^{-1}\right], T_{a r}$ - temperatura do ar $[\mathrm{K}], C_{\text {tol } / \text { hex }}$ - concentração de hexano em tolueno $\left[\mathrm{mg} \cdot \mathrm{mL}^{-1}\right], V_{h e x}-$ volume de hexano em frasco lavador $[150 \mathrm{~mL}], t_{t o l}-$ tempo de absorção de tolueno em hexano [60 s], $M_{\text {tol }}$ - massa molar do tolueno [92,14 g. $\left.\mathrm{mol}^{-1}\right]$.

Após esse tempo para absorção em hexano, as válvulas foram rapidamente manuseadas para que a corrente gasosa fluísse apenas para a coluna novamente. Da solução do frasco (7), uma alíquota de $2 \mathrm{~mL}$ foi coletada e armazenada em tubo de ensaio com tampa em refrigerador para posterior análise por CG.

Composições de saída: De acordo com o fluxograma da Figura 1, a corrente gasosa contaminada por tolueno após o frasco lavador (2), foi inserida na parte inferior da coluna de Hempel (5), onde, em contracorrente com o primeiro óleo selecionado, ocorreu a transferência de massa por absorção no solvente. O óleo virgem contido no erlenmeyer (3) foi bombeado como carga nova pela bomba peristáltica (4) para a parte superior da coluna.

Após a passagem pela vidraria, o óleo, agora contendo tolueno absorvido, escorreu pela parte inferior para o balão de fundo redondo (6) destinado ao descarte. A corrente gasosa foi liberada pela parte superior da coluna de Hempel e era conduzida para a atmosfera uma vez que a válvula 4 (V4) estivesse aberta e a válvula 5 (V5) fechada.

Para a aquisição dos dados de saída, comutou-se a direção dessa corrente para o frasco lavador contendo hexano (7b) pela rápida abertura da válvula 5 (V5) e fechamento da válvula 4 (V4). Esse procedimento se deu após cerca de 5 minutos da corrente gasosa retornar à coluna ao término da coleta de dados de entrada, garantindo o regime permanente e a expulsão do ar das mangueiras e componentes.

De maneira similar à obtenção dos dados iniciais, o período de contato entre essa corrente com o volume de $150 \mathrm{~mL}$ de hexano foi também de 60 segundos devido aos mesmos motivos. Por fim, uma amostra de $2 \mathrm{~mL}$ dessa solução foi coletada para análise por CG para a obtenção da concentração de tolueno remanescente na saída do processo.

As composições molares de tolueno nessa corrente gasosa foram calculadas por meio das mesmas Equações 1, 2 e 3, a fim de serem comparadas com os resultados obtidos pelas simulações no Aspen para cada um dos ensaios com os quatro diferentes óleos.

Para a análise de todas as amostras de hexano contaminado por tolueno coletadas na entrada e na saída da coluna de absorção e obtenção de suas respectivas concentrações, foi utilizado um equipamento de cromatografia gasosa (CG).

\subsection{Procedimento computacional}


Este tópico expõe as diretrizes para o desenvolvimento do modelo fenomenológico da coluna de absorção no software Aspen conforme o fluxograma laboratorial. Essa etapa tinha o intuito de comparar os resultados experimentais e simulados para a confirmação e escolha do óleo mais apropriado.

O modelo utilizou alguns dos resultados experimentais como dados de entrada para a realização das simulações para manter os mesmos parâmetros operacionais tais como, vazões gasosas e líquidas, pressões, temperaturas e composições de tolueno na entrada da coluna para cada tipo de solvente.

Como primeiro passo para o desenvolvimento das simulações, foram selecionados os componentes e os métodos matemáticos para cada tipo de óleo. Os componentes do sistema foram listados como basicamente ar, tolueno e óleo. Pelo fato de alguns dos solventes ensaiados não serem frequentemente utilizados ou não se encontrarem no banco de dados do programa, foi necessário selecionar seus constituintes na base de dados para que suas propriedades pudessem ser calculadas. As composições utilizadas nas simulações variam de acordo com o óleo e estão especificadas no Quadro 2. e expressas em frações mássicas:

\begin{tabular}{lll}
\hline Óleo & Composição (\% mássica) & Fonte \\
\hline de soja & $71 \%$ de ácido linoleico e $29 \%$ de ácido oleico & CAMPANELLA et al., 2010 \\
& $63,3 \%$ de n-hexacosano e $31,7 \%$ de n-tracontano $(95 \%$ de & RAY et al., 2009 \\
de reuso & $\begin{array}{l}\text { alifáticos) e 2,732\% de pireno, } 1,376 \% \text { de antraceno e } 0,892 \% \text { de } \\
\text { benzantraceno (5\% de aromáticos) }\end{array}$ & YANG et al., 2016 \\
de silicone & $100 \%$ de polidimetilsiloxano & \\
de rícino & $95 \%$ de ácido oleico e 5\% de ácido linoleico & \\
\hline
\end{tabular}

A escolha do método a ser empregado pode ser considerada uma das partes mais importantes, pois atua de maneira a definir os parâmetros envolvidos, determinando as propriedades dos componentes envolvidos e as condições de equilíbrio segundo cada equação de estado. Para o projeto, foi necessário escolher equações de estado que melhor representasse o sistema de hidrocarbonetos apolares e que determinasse as constantes físicoquímicas e as relações binárias de seus componentes. Dessa maneira, devido às diferentes naturezas e composições dos óleos utilizados, foram empregados modelos matemáticos específicos para simular cada um deles:

a) Óleo de soja: modelo de Benedict-Web-Rubin com variações de Lee-Starling por se tratar de uma equação extremamente precisa, sendo indicada para uso em sistemas apolares ou levemente polares;

b) Óleo de reuso: modelo de Maxwell-Bonnell por ser ideal para processos que utilizam hidrocarbonetos apolares e processamento de gases;

c) Óleo de silicone: modelo de Lee-Kesler-Plocker por ser ideal para sistemas apolares como em interações entre hidrocarbonetos e gases leves;

d) Óleo de rícino: modelo de Benedict-Web-Rubin com variações de Lee-Starling.

Após a seleção dos componentes e modelos matemáticos, o fluxograma representado pela Figura 2 utilizou uma coluna do tipo RadFrac para o processo, pois segue cálculos 
rigorosos de equilíbrio em sistemas contendo duas ou três fases e é indicada para a modelagem de absorvedores e strippings.

Nessa coluna foram conectadas e nomeadas as correntes de entrada e saída. As correntes de entrada no sistema foram denominadas como T-RICO (corrente gasosa de alimentação rica em tolueno) e O-POBRE (corrente líquida de alimentação livre de tolueno) e suas condições de operação tais como, temperaturas, pressões, composições e vazões, foram definidas conforme seus respectivos ensaios. Para a composição das correntes, os valores experimentais foram introduzidos de forma a facilitar o manuseio dos dados, podendo ser em forma de fluxo molar, composição molar, entre outros. Os valores das condições de processo de cada simulação se encontram na seção dos resultados.

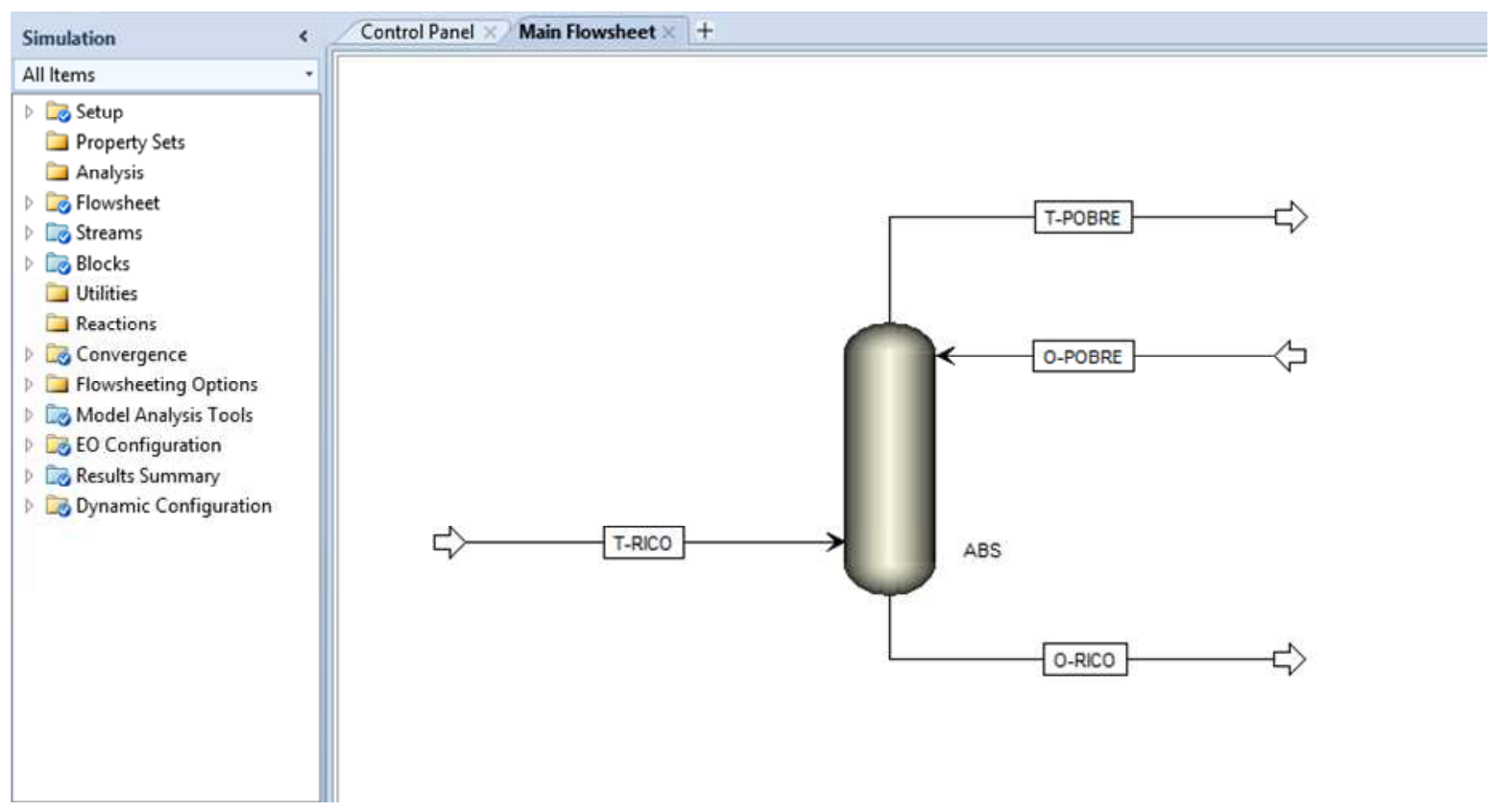

Figura 2 - Montagem do fluxograma do processo no Aspen.

Apenas uma coluna de absorção foi utilizada como operação unitária e, tratando-se de um absorvedor, o refervedor e o condensador do equipamento foram desconsiderados. A opção de cálculo foi adotada como Rate-Based na qual o absorvedor foi analisado sem a necessidade do conhecimento de fatores de eficiência dos pratos e altura das unidades de transferência (WEILAND; HATCHER, 2011). O número de estágios teóricos da coluna foi especificado, assim como o prato de alimentação das correntes, e foi necessário estabelecer apenas a pressão do primeiro estágio equivalente à pressão de saída no topo do equipamento. Como fases presentes foram selecionados apenas vapor e líquido, com apenas uma fase líquida por se tratar de sistema homogêneo.

Além disso, foram especificados o tipo de recheio utilizado e suas dimensões e o volume interno de enchimento da coluna. O Aspen calcula o fator de empacotamento do recheio, o qual varia de acordo com o material e fabricante através de sua própria base de dados. Para finalizar a configuração do processo, o tipo de fluxo foi selecionado como contracorrente e a correlação adotada para o cálculo dos coeficientes de transferência de massa e de área interfacial do recheio foi Billet and Schultes. 


\subsection{Análise de sensibilidade}

O Aspen disponibiliza algumas ferramentas para a análise do modelo a fim de otimizar ou analisar o processo estudado. Uma dessas ferramentas é a análise de sensibilidade na qual é possível observar o comportamento do sistema de acordo com um distúrbio aplicado em alguma das condições do processo.

No projeto, essa análise foi realizada apenas para o óleo de melhor desempenho. Para isso, foram criados sistemas hipotéticos nos quais as dimensões das colunas de enchimento e as vazões de alimentação atuaram como dados de entrada para as análises. Os diâmetros dos recheios utilizados foram escolhidos de forma a não exceder $1 / 8$ dos diâmetros de suas respectivas colunas (CALDAS, 1988).

A análise requeria a seleção da variável manipulada para sofrer os distúrbios, considerando seus limites para variação e seu incremento para tal ação. Assim, foram aplicadas variações na vazão de alimentação de óleo na coluna com o intuito de observar a influência na composição da corrente gasosa de saída, a variável medida, e, consequentemente, na porcentagem de absorção.

Os resultados foram manipulados de forma a apresentarem as variáveis de interesse, os quais encontram-se na seção de resultados, bem como as especificações dos sistemas hipotéticos e os gráficos gerados através dessa análise.

\section{RESULTADOS E DISCUSSÃO}

\subsection{Resultados laboratoriais}

Em suma, foram adotadas as seguintes hipóteses para a obtenção dos resultados: vazões gasosas e líquidas constantes, total absorção de tolueno por hexano nos frascos lavadores, solução diluída de tolueno em hexano, volume de hexano invariável durante o tempo de amostragem e perda de carga pelo sistema da unidade laboratorial desprezível.

Ensaios de absorção de tolueno em coluna laboratorial: A Tabela 1 apresenta as condições operacionais dos ensaios de cada óleo utilizado. Devido à perda de carga desprezível ao longo do sistema, a pressão manométrica da corrente gasosa foi considerada igual à pressão atmosférica local. A temperatura foi medida no ponto de saída do compressor de ar, mantendo-se constante e igual em todos os ensaios e, conforme descrito no procedimento, as vazões gasosas e líquidas foram obtidas através do método de deslocamento de nível em proveta.

Tabela 1 - Condições operacionais para os ensaios laboratoriais.

\begin{tabular}{ccccc}
\hline Solvente & $\mathbf{P}(\mathbf{m m H g})$ & $\mathbf{T}\left({ }^{\circ} \mathbf{C}\right)$ & $\mathbf{V}_{\text {ar }}(\mathbf{m L} / \mathbf{s})$ & $\mathbf{V}_{\text {óleo }}(\mathbf{m L} / \mathbf{s})$ \\
\hline Soja & 688,9 & 33,0 & $29,0 \pm 0,5$ & $0,52 \pm 0,00$ \\
Reuso & 695,6 & 33,0 & $30,7 \pm 1,2$ & $0,52 \pm 0,01$ \\
Silicone & 695,6 & 33,0 & $29,3 \pm 0,6$ & $0,51 \pm 0,01$ \\
Rícino & 688,9 & 33,0 & $30,4 \pm 1,1$ & $0,51 \pm 0,03$ \\
\hline
\end{tabular}


Em conformidade com o proposto, fica constatado pela análise dos resultados acima que, devido as suas pequenas divergências, todos os experimentos foram realizados utilizando parâmetros operacionais similares.

A Equação 2 e os valores da Tabela 1 foram utilizados para o cálculo da vazão molar de ar que se mantém constante por todo o sistema por não sofrer absorção, correspondendo a $1,05.10^{-3} \mathrm{~mol} / \mathrm{s}$ para o óleo de soja, $1,12.10^{-3} \mathrm{~mol} / \mathrm{s}$ para o óleo de reuso, $1,07.10^{-3} \mathrm{~mol} / \mathrm{s}$ para o óleo de silicone e $1,10.10^{-3} \mathrm{~mol} / \mathrm{s}$ para o óleo de rícino.

Seguindo os procedimentos para a aquisição de resultados de entrada e saída e através das Equações 1, 2 e 3, as Tabelas 2 e 3 fornecem os valores médios das composições de tolueno em hexano $\left(\mathrm{C}_{\mathrm{tol} / \mathrm{hex}}\right)$, as quantidades molares de tolueno $\left(\mathrm{n}_{\mathrm{tol}}\right)$ e suas frações molares $\left(\mathrm{y}_{\text {tol/ar }}\right)$ nas correntes gasosas de entrada e saída da coluna, respectivamente.

Tabela 2 - Composições médias de tolueno na corrente gasosa de entrada.

\begin{tabular}{cccc}
\hline Solvente & $\mathbf{C}_{\mathrm{e} \text { tol/hex }}(\mathbf{m g} / \mathbf{m L})$ & $\mathbf{n}_{\mathrm{e} \text { tol.10 }} \mathbf{1 0}(\mathbf{m o l} / \mathbf{s})$ & $\mathbf{y}_{\mathrm{e} \text { tol/ar }} \mathbf{( \% )}$ \\
\hline Soja & $0,356 \pm 0,029$ & $9,65 \pm 0,78$ & $0,915 \pm 0,073$ \\
Reuso & $0,402 \pm 0,013$ & $10,92 \pm 0,35$ & $0,966 \pm 0,031$ \\
Silicone & $0,306 \pm 0,038$ & $8,29 \pm 1,03$ & $0,772 \pm 0,095$ \\
Rícino & $0,447 \pm 0,056$ & $12,13 \pm 1,51$ & $1,095 \pm 0,134$ \\
\hline
\end{tabular}

Tabela 3 - Composições médias de tolueno na corrente gasosa de saída.

\begin{tabular}{cccc}
\hline Solvente & $\mathbf{C}_{\text {s tol/hex }}(\mathbf{m g} / \mathbf{m L})$ & $\mathbf{n}_{\text {s tol. }} \mathbf{1 0} \mathbf{6}(\mathbf{m o l} / \mathbf{s})$ & $\mathbf{y}_{\text {s tol/ar }}(\mathbf{\%})$ \\
\hline Soja & $0,128 \pm 0,005$ & $3,46 \pm 0,13$ & $0,330 \pm 0,012$ \\
Reuso & $0,148 \pm 0,004$ & $4,01 \pm 0,10$ & $0,357 \pm 0,009$ \\
Silicone & $0,123 \pm 0,001$ & $3,34 \pm 0,03$ & $0,312 \pm 0,003$ \\
Rícino & $0,143 \pm 0,006$ & $3,88 \pm 0,15$ & $0,353 \pm 0,014$ \\
\hline
\end{tabular}

Os valores das frações molares de tolueno de entrada seguem para serem utilizados nas simulações com o programa Aspen para posterior comparação de resultados de absorção.

Avaliação de eficiência de absorção para seleção de melhor óleo: Devido à semelhança na operabilidade dos ensaios, os resultados obtidos na etapa laboratorial representam um indicativo da performance dos solventes utilizados. Através dos dados das tabelas acima e da Equação 4, a Tabela 4 expressa os resultados obtidos dos cálculos de absorção de tolueno em óleo.

$\%$ Absorção $=\frac{\dot{n}_{\text {etol }}-\dot{n}_{\text {stol }}}{\dot{n}_{\text {etol }}} 100 \%$

Onde: $\dot{n}_{\text {etol }}$ - vazão molar média de tolueno na corrente gasosa de entrada da coluna $\left(\mathrm{mol} \cdot \mathrm{s}^{-1}\right)$, $\dot{n}_{s t o l}$ - vazão molar média de tolueno na corrente gasosa de saída da coluna $\left(\mathrm{mol} \cdot \mathrm{s}^{-1}\right)$ 
Tabela 4 - Absorção média de tolueno pelos solventes utilizados nos ensaios.

\begin{tabular}{cccc}
\hline Óleo & $\mathbf{n}_{\mathbf{e}}$ tol $\times \mathbf{1 0}^{\mathbf{6}} \mathbf{( \mathbf { m o l } / \mathbf { s } )}$ & $\mathbf{n}_{\mathbf{s} \text { tol }} \times \mathbf{1 0}^{\mathbf{6}}(\mathbf{m o l} / \mathbf{s})$ & Absorção $\mathbf{~ \% ) ~}$ \\
\hline Soja & $9,65 \pm 0,78$ & $3,46 \pm 0,13$ & $63,9 \pm 3,2$ \\
Reuso & $10,92 \pm 0,35$ & $4,01 \pm 0,10$ & $63,3 \pm 2,0$ \\
Silicone & $8,29 \pm 1,03$ & $3,34 \pm 0,03$ & $59,3 \pm 5,7$ \\
Rícino & $12,13 \pm 1,51$ & $3,88 \pm 0,15$ & $67,6 \pm 4,8$ \\
\hline
\end{tabular}

Para uma melhor visualização dos resultados de absorção, o gráfico da Figura 3 a seguir relaciona percentualmente os valores médios de absorção de tolueno nos óleos entre si, apontando também suas variâncias.

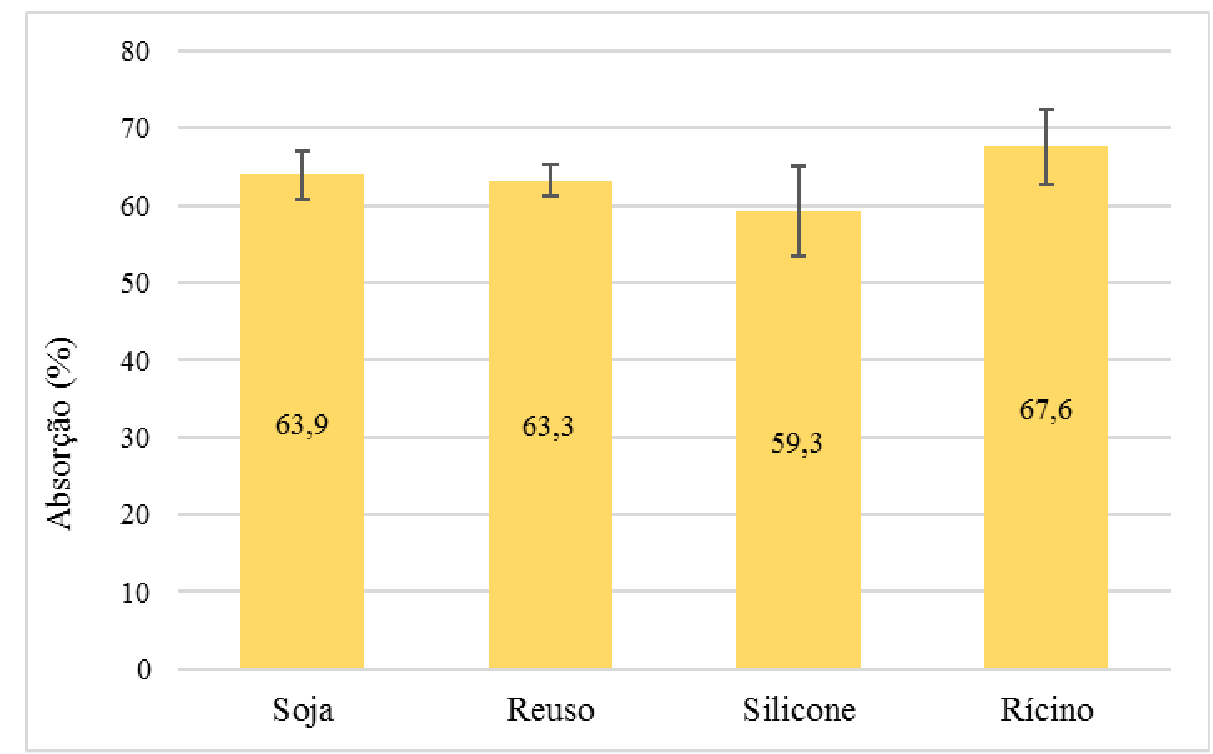

Figura 3 - Resultados laboratoriais de absorção de tolueno nos óleos utilizados.

Uma maneira de se avaliar o desempenho dos óleos na absorção de tolueno é por meio da análise da variância de seus resultados, no qual podem ser observados os desvios de absorção em relação aos seus valores médios. A Figura 4 representa um diagrama que aponta pela área cinza a região em que os solventes demonstram um comportamento similar na absorção do contaminante.

Pela análise entre as médias e desvios acima, a estatística evidencia que os quatro óleos apresentam o mesmo desempenho na absorção de tolueno. Contudo, para a determinação do óleo mais eficiente econômica e ecologicamente, outros critérios de escolha devem ser considerados. 


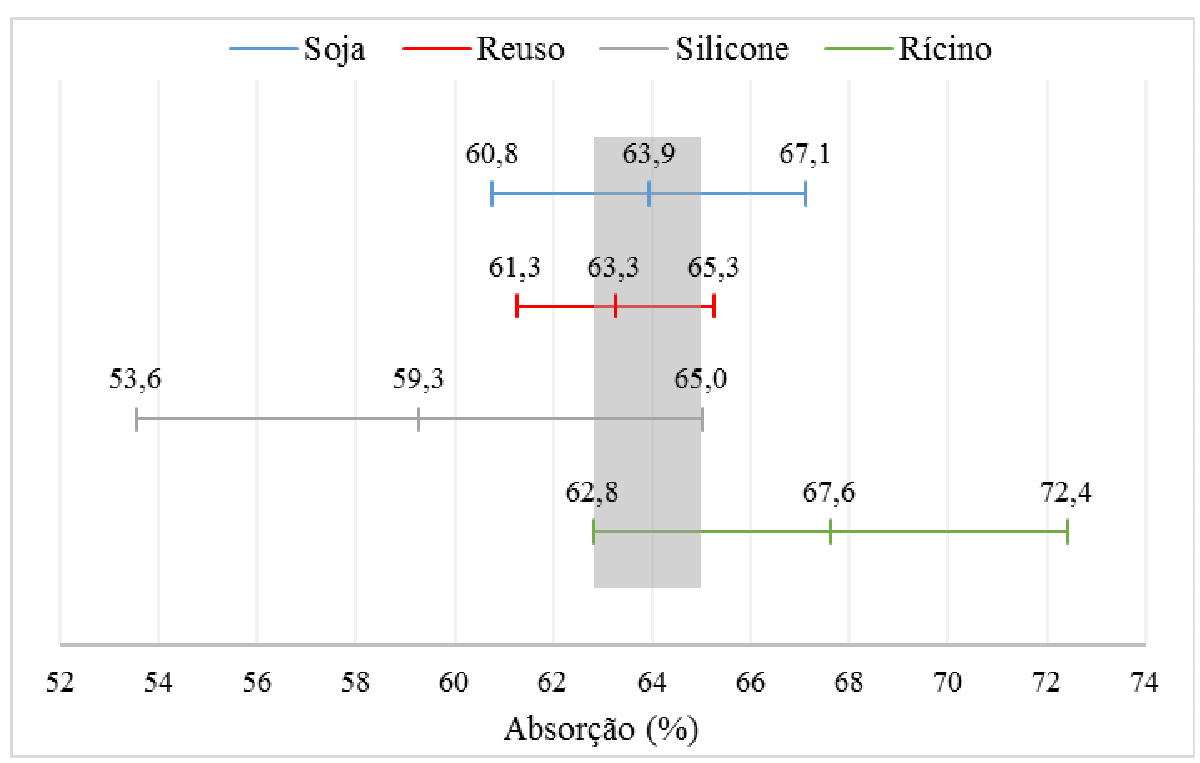

Figura 4 - Diagrama de variância dos resultados de absorção.

A Tabela 5 representa uma matriz contendo quatro fatores para a escolha do óleo. O critério ambiental é essencial, pois analisa o óleo desde o seu impacto durante a fabricação até a utilização de seu resíduo químico. Sabendo que em uma aplicação real a quantidade do solvente a ser utilizado não é pequena, o custo se mostra como um dado importante de decisão. Os critérios de menor influência como fluidez e disponibilidade, representam apenas a facilidade na operação com os óleos.

Um valor foi estabelecido como peso para cada critério obedecendo a ordem numérica crescente para o fator de maior importância, ou seja, quanto maior o peso atribuído, maior a importância do critério. O mesmo conceito foi aplicado aos óleos utilizados para diferenciálos em uma mesma categoria de escolha. Por fim, para seleção do óleo mais eficiente, foi verificado o maior resultado entre a soma dos produtos, sendo este produto dado pela multiplicação do peso de cada critério com a nota conferida a cada óleo.

Tabela 5 - Matriz de seleção para determinação de solvente mais apropriado.

\begin{tabular}{lccccc}
\hline Critério & Peso & Soja & Reuso & Silicone & Rícino \\
\hline Ambiental & 4 & 3 & 4 & 1 & 2 \\
Custo & 3 & 3 & 4 & 1 & 2 \\
Fluidez & 2 & 4 & 3 & 2 & 1 \\
Disponibilidade & 1 & 4 & 3 & 2 & 1 \\
\hline Soma dos produtos & & 33 & 37 & 13 & 17 \\
\hline
\end{tabular}

A partir da tabela acima, fica determinado que o solvente mais eficaz economicamente e ecologicamente para aplicações industriais na absorção de VOC é o óleo de reuso, uma vez que é um resíduo químico gerado por motores automotivos e que pode ser coletado praticamente sem custo algum. Além disso, é um óleo de fácil aquisição e operação verificado experimentalmente. 


\subsection{Resultados computacionais}

Conforme as diretrizes para o modelamento e simulação da coluna laboratorial, as simulações foram realizadas com base nos dados experimentais de pressão, temperatura, vazão e composição apresentados na Tabela 1 e 2 e nas dimensões da coluna da unidade laboratorial a fim de, posteriormente, se realizar um estudo comparativo entre os resultados laboratoriais e os obtidos pelas simulações.

Através dos dados obtidos com essa metodologia e utilizando-se a Equação 4, as absorções de tolueno pelos solventes foram calculadas com as quantidades molares de tolueno na entrada e na saída de cada simulação e estão apresentadas na Tabela 6 a seguir.

Tabela 6 - Absorção de tolueno pelos solventes utilizados nas simulações.

\begin{tabular}{cccc}
\hline Óleo & $\mathbf{n}_{\mathrm{e} \mathrm{tol}} \times \mathbf{1 0}^{\mathbf{6}}(\mathbf{m o l} / \mathbf{s})$ & $\mathbf{n}_{\mathbf{s} \text { tol }} \times \mathbf{1 0}^{\mathbf{6}}(\mathbf{m o l} / \mathbf{s})$ & Absorção $(\mathbf{\%})$ \\
\hline Soja & 9,65 & 1,92 & 80,1 \\
Reuso & 10,92 & 3,89 & 64,3 \\
Silicone & 8,29 & 4,18 & 49,5 \\
Rícino & 12,13 & 2,44 & 79,8 \\
\hline
\end{tabular}

Não eram esperados resultados positivos para o óleo de soja por se tratar de um óleo de origem vegetal. Suas cadeias carbônicas poderiam não conter afinidade com o tolueno presente na fase gasosa e, assim, comprometer a absorção.

Pelo fato de o óleo de reuso ser composto por uma mistura de hidrocarbonetos e possivelmente possuir afinidade com tolueno, bons resultados eram aguardados para esse solvente, sendo viável sua utilização como substituto para outros óleos. A quantidade de tolueno presente na corrente gasosa de saída indicada na tabela acima comprova que é possível a utilização do óleo de reuso pelo ponto de vista técnico.

A absorção de tolueno utilizando o óleo de silicone ficou abaixo do esperado, pois teoricamente e de acordo com os artigos estudados, os melhores resultados poderiam ocorrer pelo uso do óleo de silicone, contrário ao observado experimentalmente e pela simulação.

A partir dos resultados observados para o óleo de soja, foi previsto um comportamento similar para o óleo de rícino por apresentar certas semelhanças entre seus componentes e também por ser um óleo de origem vegetal. Dessa maneira e analisando os resultados acima, é possível a utilização do óleo de rícino para realizar a operação de absorção tecnicamente.

De acordo com o previsto, em todas as simulações, a perda de carga na coluna de absorção foi desprezível também para o processo computacional.

\subsection{Comparações laboratoriais e computacionais}

Utilizando os valores das Tabela 4 e 6, a comparação entre os valores de absorção obtidos experimentalmente e pelas simulações pode ser avaliada através do desvio de seus resultados. Esse desvio consiste no módulo da diferença entre as absorções em cada óleo e estão demonstrados pela Tabela 7. 
Tabela 7 - Diferença entre absorção laboratorial (AL) e computacional (AC) em valor absoluto.

\begin{tabular}{cccc}
\hline Solvente & AL (\%) & AC (\%) & Desvio (\%) \\
\hline Soja & 63,9 & 80,1 & 16,2 \\
Reuso & 63,3 & 64,3 & 1,0 \\
Silicone & 59,3 & 49,5 & 9,8 \\
Rícino & 67,6 & 79,8 & 12,2 \\
\hline
\end{tabular}

No gráfico da Figura 5, pode ser visualizada a diferença entre os resultados dos ensaios de laboratório e os das simulações no Aspen.

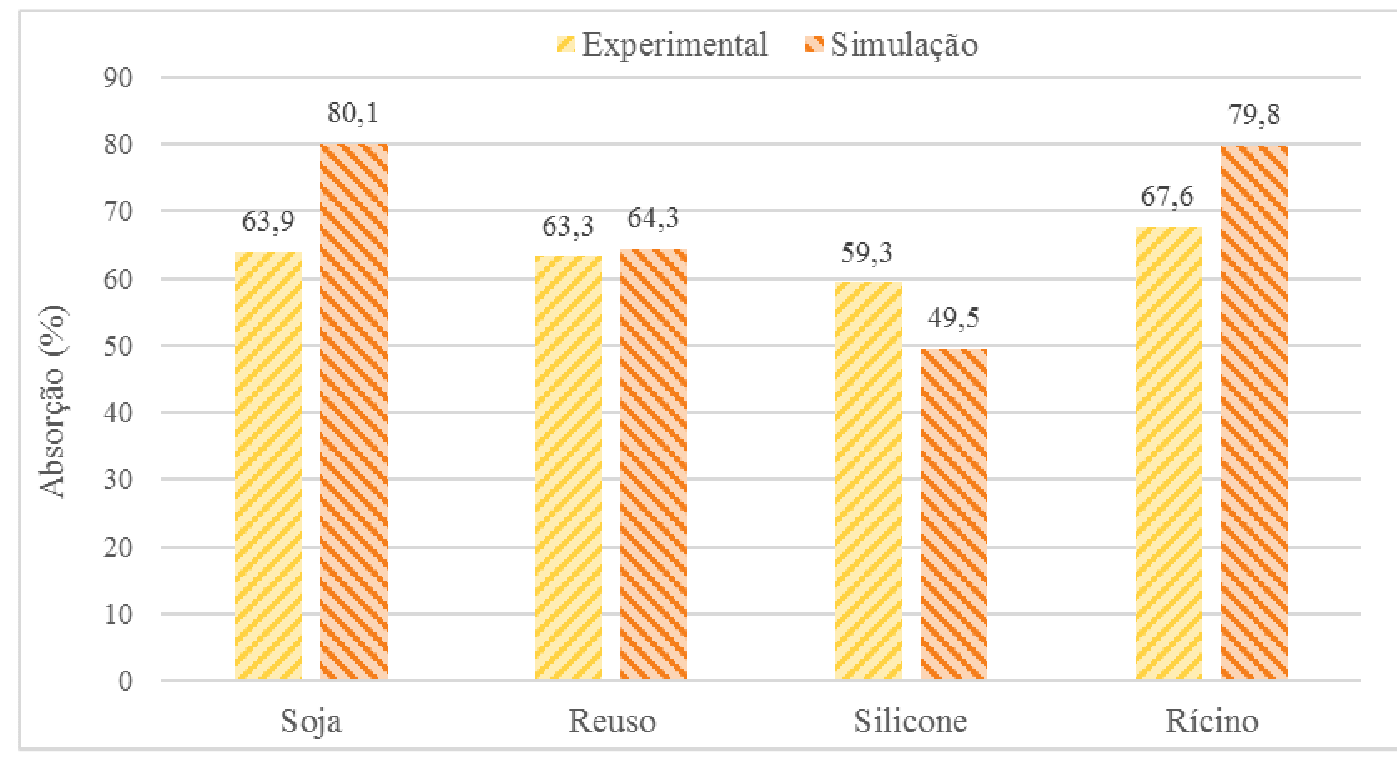

Figura 5 - Comparação de resultados laboratoriais e computacionais de absorção.

Através da tabela e do gráfico apresentados, verificou-se que o óleo de reuso obteve o menor desvio em relação aos demais óleos, os óleos de silicone e rícino apresentaram diferenças próximas a $10 \%$ e o óleo de soja apresentou o pior valor para essa avaliação.

Tais desvios podem ser decorrentes do modelo matemático utilizado e também da composição para cada óleo determinada no simulador, porém são satisfatórios principalmente para o óleo de reuso que possui uma diferença de apenas $1 \%$. Portanto, considerando que esse óleo foi selecionado como o solvente mais apropriado para a absorção de VOC, a análise de sensibilidade realizada pelo modelo construído no simulador para o óleo em questão não deve apresentar resultados discrepantes do que ocorre na realidade em uma coluna de escala industrial, garantindo assim uma grande confiabilidade em seus resultados.

\subsection{Análise de sensibilidade}

Como proposto, foi realizado uma análise de sensibilidade na qual alguns parâmetros do processo e da coluna de absorção foram variados com o objetivo de se estudar o comportamento do sistema. 
Adotando a composição de entrada como sendo a mesma determinada experimentalmente e utilizando uma vazão gasosa de $20 \mathrm{~kg} / \mathrm{h}$, foram definidas colunas hipotéticas tomando como base parâmetros aproximados de um processo industrial onde pode ser empregado este estudo. Para a análise de sensibilidade, foram variadas as vazões de líquido a fim de se obter seus respectivos resultados de absorção.

Diferentes curvas poderiam ser obtidas pela alteração de outros parâmetros operacionais tais como, temperatura das correntes e pressão na coluna. Contudo, foi escolhido utilizar valores de temperatura e pressão semelhantes aos utilizados nos experimentos.

Na Tabela 8 abaixo estão descritas as dimensões das colunas hipotéticas criadas para a análise de sensibilidade a qual pode ser analisada pelas curvas da Figura 13 (a).

Tabela 8 - Dimensões das colunas de absorção hipotéticas industriais.

\begin{tabular}{cccc}
\hline Coluna & Altura $(\mathbf{m})$ & Diâmetro $(\mathbf{m})$ & Diâmetro do recheio $(\mathbf{m m})$ \\
\hline A & 4,0 & 0,3 & 30 \\
B & 2,5 & 0,3 & 30 \\
C & 2,0 & 0,5 & 50 \\
D & 1,0 & 0,3 & 30 \\
\hline
\end{tabular}
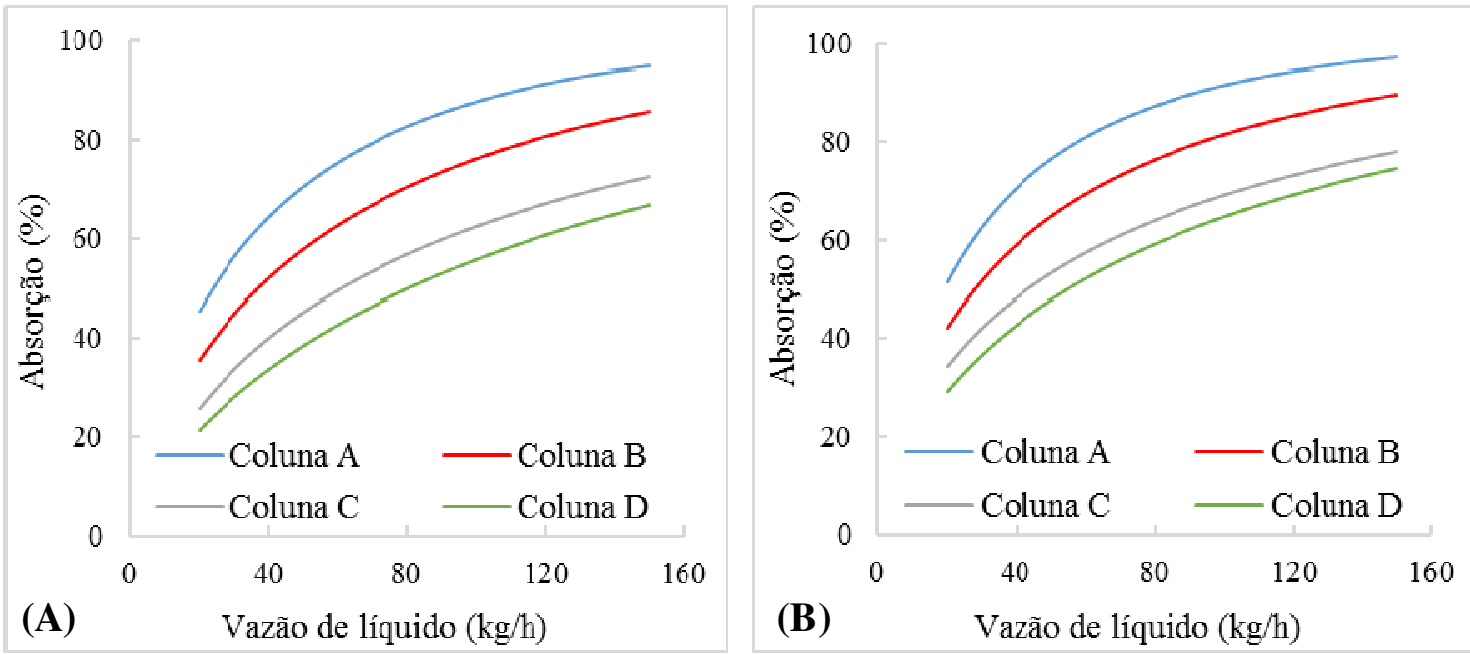

Figura 13 - Análise de sensibilidade com corrente contaminada (a) e saturada (b) por tolueno.

Para uma análise industrial utilizando as mesmas colunas, visando um pior caso, na qual o ar poderia entrar saturado com tolueno, foi realizada uma análise para observar o comportamento do sistema mediante essa condição conforme a Figura 13 (b). Pela lei de Dalton, através dos dados de pressão máxima de vapor de tolueno e da pressão local como sendo $688,9 \mathrm{mmHg}$, é possível o cálculo da fração molar de tolueno em ar que serve como dado de entrada para a simulação.

Entre as curvas das Figuras 13, para o caso no qual o ar entra saturado, é observada uma melhor absorção em relação à análise menos concentrada em tolueno quando comparadas em uma mesma vazão de líquido. Esse fenômeno no qual é necessária uma 
menor vazão de solvente mesmo trabalhando com concentrações elevadas para obter maiores valores de absorção, pode ser explicado pela lei de Fick conforme descrito pela equação 1 , uma vez que, com uma concentração inicial maior, consequentemente, o gradiente de concentração aumenta. Como descrito na equação, o fluxo de matéria é diretamente proporcional ao gradiente de concentração, então, era esperado que se obtivesse melhores valores de absorção para o caso onde a corrente gasosa entra mais concentrada em soluto.

Deve-se levar em conta o diâmetro do recheio uma vez que pequeno demais em relação ao diâmetro da coluna, pode causar inundação ou sendo grande demais pode causar caminhos preferenciais, ambos fenômenos indesejados para essa operação unitária (CALDAS, 1988).

Outro fator importante a ser observado é a influência da altura da coluna na absorção de tolueno. As curvas demonstram que quanto maior a altura, maior é a absorção do contaminante. Esse comportamento é coerente, uma vez que quanto maior a altura da coluna, maior a quantidade de recheio e, consequentemente, maior a área superficial de contato entre o soluto e o solvente, favorecendo assim a absorção.

\section{CONCLUSÃO}

A partir dos resultados, tanto computacionais como os obtidos experimentalmente, notou-se uma tendência de que os óleos são uma boa alternativa para a remoção de VOC em correntes contaminadas. O uso desse tipo de operação unitária se torna extremamente viável uma vez que por se tratar de uma operação muito bem difundida no meio da engenharia química, os estudos para o uso em escala real se torna simplificado pela existência de diversos acessórios que poderiam ainda melhorar o desempenho, diminuindo custos e melhorando o impacto ambiental da indústria que geram os VOC como subprodutos indesejados.

Os resultados obtidos experimentalmente alcançaram valores com baixos desvios com relação aos resultados obtidos para as simulações por se tratar de uma coluna em escala laboratorial, com pequeno diâmetro e pequena altura, obteve-se valores de absorção além do esperado. Os resultados obtidos através dos experimentos podem levar a construção de outros sistemas de absorção, assim como foram feitos na análise de sensibilidade, na qual valendose da proporção, a simulação obteve um resultado proporcional.

A comprovação com a simulação nos direciona para uma reafirmação de que as hipóteses adotadas foram satisfatórias e, a partir disso, o uso do modelo em escala industrial se torna promissor, podendo facilitar a construção de uma operação que requer o uso da absorção para purificação da corrente gasosa de saída dos processos industriais, diminuindo os gastos necessários com o dimensionamento para implementação da operação.

A aplicação de uma operação real industrialmente deve levar em conta os custos, as disponibilidades e as condições operacionais para ser viável a troca por um processo já existente. $\mathrm{O}$ óleo de reuso destacou-se para essas condições, uma vez que haveria uma destinação nobre para um resíduo que hoje em dia causa sérias preocupações no quesito ambiental e, por esse fator, gera outra vantagem, pois o mesmo não tem hoje valor agregado como matéria prima para processos como este de absorção em colunas de enchimento. 
As análises de sensibilidade obtidas por esse trabalho nos geram uma boa diretriz, pois é possível observar que em um processo real, será viável obter valores de absorção próximo a $100 \%$. Porém, ao assunto tratado, cabe a reavaliação para estudos futuros, como otimizações de um processo, uma análise de custos melhor elaborada e até mesmo uma melhor análise química do óleo a ser escolhido. Cabe ainda uma análise de um processo conjunto de recuperação do tolueno retido no solvente adotado, e uma análise de desempenho real, levando em conta outros fatores de como o rendimento seria afetado por uma saturação do soluto no solvente.

\section{AGRADECIMENTOS}

Ao Centro Universitário FEI pelo suporte para o desenvolvimento do trabalho.

\section{REFERÊNCIAS}

CALDAS, J. N.; LACERDA, A. I. Torres recheadas. 1. ed. Rio de Janeiro: Editora Jr, 1988. CAMPANELLA, A.; RUSTOY, E; BALDESSARI, A.; BALTANÁS, M. A. Lubricants from chemically modified vegetable oils. Bioresource Technology, v. 101, p. 245-254, jan. 2010.

DARRACQ, G.; COUVERT, A.; COURIOL, C.; AMRANE, A.; THOMAS, D.; DUMONT, E.; ANDRÈS, Y.; LE CLOIREC, P. Silicone oil: An effective absorbent for the removal of hydrophobic volatile organic compounds. Journal of Chemical Technology and Biotechnology, v. 85, p. 309-313, 12 jan. 2010.

DUMONT, E. et al. VOC absorption in a countercurrent packed-bed column using water;silicone oil mixtures: Influence of silicone oil volume fraction. Chemical Engineering Journal, v. 168, p. 241-248, 15 mar. 2011. Disponível em: $<$ http://www.sciencedirect.com/science/article/pii/S138589471100009X>. Acesso em: 22 ago. 2015.

OU, J.; ZHENG, J.; LI, R.; HUANG, X.; ZHONG, Z.; ZHONG, L.; LIN, H. Speciated OVOC and VOC emission inventories and their implications for reactivity-based ozone control strategy in the Pearl River Delta region, China. Science of The Total Environment, Hong Kong, v. 530-531, p. 393-402, 15 out. 2015.

RAY, S. S.; PANDEY, N. K.; CHATTERJEE, A. K. Effect of aromatics and iso-alkanes on the pour point of different types of lube oils. Fuel, v. 88, p. 1629-1633, set. 2009.

SÃO PAULO (Estado). Decreto n. 8.468, de 8 de setembro de 1976. Disponível em: $<$ http://licenciamento.cetesb.sp.gov.br/Servicos/licenciamento/postos/legislacao/Decret o_Estadual_8468_76.pdf>. Acesso em: 15 out. 2015.

VUONG, M. D. et al. Determination of the Henry's constant and the mass transfer rate of VOCs in solvents. Chemical Engineering Journal, v. 150, p. 426-430, 2009. Disponível em:

<http://www.sciencedirect.com/science/article/pii/S138589470900058>. Acesso em: 12 ago. 2015.

WEILAND, R. H.; HATCHER, N. A. What are the benefits from mass transfer rate-based simulation? Hydrocarbon Processing, Houston, p. 43-49, jul. 2011. Disponível em: $<$ http://www.ogtrt.com/files/publications/w20777.pdf>. Acesso em: 01 fev. 2016.

YANG, C. et al. Characterization and differentiation of chemical fingerprints of virgin and used lubricating oils for identification of contamination or adulteration sources. Fuel, v. 
163, p. 271-281, 1 jan. 2016. Disponível em:

<http://www.sciencedirect.com/science/article/pii/S0016236115009679>. Acesso em: 29 jan. 2016.

\title{
VOLATILE ORGANIC COMPOUNDSREDUCTION THROUGH OIL ABSORPTION IN PACKAGING COLUMNS
}

\author{
L. G. RIBEIRO ${ }^{1, *}$, H. S. MONTEIRO ${ }^{1}$, N. S. DENARDI ${ }^{1}$, W. HUNG-HSU ${ }^{1}$ e \\ Y. C. ROCHA ${ }^{1}$
}
${ }^{1}$ FEI University, Department of Chemical Engineering
*E-mail: luciano.ribeiro0312@gmail.com

\begin{abstract}
This project proposed the study of the performance of packed columns in order to reduce the emission of VOCs present in industrial gas streams by means of absorption in suitable solvent. Due to these compounds are hydrophobic, the solvents were selected because of their similarity to VOCs regarding to polarity and they were: soybean oil, automotive used oil, silicone oil and castor oil. The methodology consisted of assays in a laboratory-scale absorption column, maintaining the same operational parameters among each experiment. Using these parameters and physical characteristics of the laboratory equipment, the experimental results were compared with those obtained by the simulations in Aspen Plus for the possibility of application in real process. Through the absorption performance and environmental and economic criteria, the automotive used oil presented better potential for this purpose due to the fact it is a chemical residue that can be used to mitigate the proposed environmental problem
\end{abstract}

KEYWORDS: Volatile organic compounds ; Toluene ; absorption column 